\title{
Wpływ aktywacji powierzchni aluminium 7075 na wytrzymałość połączenia klejowego
}

\author{
The investigation of influence of surface activation \\ of aluminum 7075 on strength of bonded joint
}

\section{Streszczenie}

W artykule przedstawiono wyniki badań wytrzymałości statycznej na ścinanie połączeń klejowych zakładkowych wykonanych ze stopu aluminium 7075 . Badania miały charakter porównawczy i dotyczyły przebadania wpływu aktywacji powierzchni klejonej przy zastosowaniu plazmy niskotemperaturowej z próbkami niepoddanymi aktywowaniu. Zastosowano 3 rodzaje materiałów adhezyjnych. Na podstawie przeprowadzonych badań stwierdzono wzrost swobodnej energii powierzchniowej dla próbek modyfikowanych plazmą niskotemperaturową oraz dla 2 z 3 badanych klejów wzrost wytrzymałości połączenia.

Słowa kluczowe: plazma niskotemperaturowa; aktywacja powierzchni; połączenie klejowe; aluminium 7075

\begin{abstract}
The paper presents the results of the static strength test on shear adhesion bonded joints made of aluminum alloy 7075. The tests were of a comparative nature and examined the effect of surface activation using low temperature plasma with non-activated samples. Three types of adhesives were used. Based on the studies, the increase of free surface energy for low temperature plasma samples and for 2 of the 3 tested adhesives increased the strength of the joint were observed.
\end{abstract}

Keywords: low temperature plasma; surface activation; adhesion bonded joint; aluminum alloy 7075

\section{Wstęp}

Połączenia adhezyjne znajdują coraz szersze zastosowanie w wielu gałęziach przemysłu. Jest to związane $z$ wieloma zaletami takich połączeń, do których przede wszystkim należy możliwość łączenia materiałów różnoimiennych, możliwość doboru kleju do warunków eksploatacji połączenia, przenoszenie obciążeń przez całą powierzchnię złącza, a także szczelność połączenia. Do wad w szczególności należy konieczność zachowania odpowiedniego reżimu procesu technologicznego wytwarzania połączenia klejowego, w zależności od stosowanych materiałów występuje zwykle konieczność przygotowania powierzchni łączonych odpowiednimi technikami [5,13]. Badacze wskazują również na konieczność uwzględnienia środowiska użytkowania, ze względu na wrażliwość połączenia klejowego na oddziaływanie podwyższonej temperatury $[6,8]$. Metody przygotowania powierzchni można zasadniczo podzielić na 2 grupy. Do grupy 1 należą metody, których celem jest rozwinięcie powierzchni, co zwykle jest też związane z uzyskaniem powierzchni chropowatej, czego efektem jest zwiększony udział adhezji mechanicznej. Rozwinięcie powierzchni jest zwykle realizowane przy udziale mechanicznych metod obróbki powierzchni narzędziami nasypowymi lub metodami obróbki strumieniowo-ściernej [6,9]. Niestety należą one do metod pracochłonnych i komplikujących proces wytwórczy. Do drugiej grupy metod należą wszelkie metody chemiczne przygotowania powierzchni, czego efektem jest aktywacja powierzchni objawiająca się zwykle zwiększeniem polarności. Do metod chemicznych zaliczamy modyfikację powierzchni przez zastosowanie trawienia roztworami trawiącymi na bazie kwasów i ich mieszanin, a także nakładanie środków proadhezyjnych (np. związków silanowych), których celem jest uzyskanie na powierzchniach łączonych korzystnych warunków sprzyjających zwiększeniu adhezji tzw. właściwej. Metody chemiczne ze względu na występowanie różnych substancji chemicznych, o różnym stopniu szkodliwości zarówno dla otoczenia, jak i dla człowieka wymuszają stosowanie skomplikowanych instalacji procesowych, co również podraża całościowo proces wytwórczy.

Prezentowany artykuł dotyczy zbadania możliwości aktywowania powierzchni stopu aluminium 7075 przy zastosowaniu plazmy niskotemperaturowej. Plazma, ze względu na odmienne od fazy stałej, ciekłej i gazowej właściwości, powstaje w temperaturach, w których średnie energie kinetyczne cząstek przekraczają wartość potencjału jonizacyjnego.

Dr hab. inż. Zbigniew Zimniak, prof. PWr; dr inż. Roman Wróblewski - Politechnika Wrocławska.

Autor korespondencyjny/Corresponding author. zbigniew.zimniak@pwr.edu.pl 
Plazma niskotemperaturowa jest najczęściej gazem zjonizowanym w niewielkim stopniu, o dużej lub bardzo dużej zawartości cząstek neutralnych, w skład której wchodzą jądra atomów, cząstki elementarne, a także, atomy, ich jony oraz cząsteczki. Zastosowanie takiej plazmy pozwala na zwiększenie energii powierzchniowej łączonych materiałów, co przyczyni się do uzyskania dobrej jakości spoiny klejowej. Plazma tego typu stosowana była do tej pory do obróbki powierzchni tworzyw sztucznych w celu otrzymywania specjalnych własności potrzebnych do procesów klejenia, czyszczenia czy poprawy zwilżalności lub ścieralności $[3 \div 4,7,10 \div 12]$.

Proces aktywacji powierzchni przy pomocy plazmy niskotemperaturowej jest procesem relatywnie łatwym do zastosowania, w minimalnym stopniu komplikujący proces wytwórczy. Aktywacja powierzchni z wykorzystaniem plazmy niskotemperaturowej jest już stosowana do aktywacji powierzchni materiałów polimerowych, ale w odniesieniu do metali na chwilę obecną wykorzystywana jest niewielkim stopniu.

\section{Metodyka badań}

Próbki użyte do badań zostały wykonane ze stopu aluminium 7075, o wymiarach $25 \times 60 \times 2 \mathrm{~mm}$. Po zdjęciu folii ochronnej próbki oczyszczono alkoholem etylowym. W tablicy I przedstawiono skład chemiczny stopu 7075, tabelę opracowano na podstawie certyfikatu materiału.

W tablicy II zebrano wybrane własności mechaniczne stopu 7075.

Do pomiarów kąta zwilżania powierzchni stopu 7075 oraz do wyznaczania swobodnej energii powierzchniowej (SEP) zastosowano goniometr Krüss DSAHT1200 wraz z oprogramowaniem firmowym DSA3. Do pomiarów wybrano 4 ciecze pomiarowe o znanej wartości energii powierzchniowej oraz o znanych wartościach części polarnej i części dyspersyjnej. Do badań użyto:

- wody destylowanej, dla której: swobodna energia powierzchniowa wynosi $\gamma_{w}=72,8\left[\mathrm{~mJ} / \mathrm{m}^{2}\right]$, składowa dyspersyjna wynosi $\gamma_{w D}=21,8\left[\mathrm{~mJ} / \mathrm{m}^{2}\right]$, składowa polarna wynosi $\gamma_{\mathrm{wP}}=51,0\left[\mathrm{~mJ} / \mathrm{m}^{2}\right]$;

- dijodometanu, dla którego: swobodna energia powierzchniowa wynosi $\gamma_{w}=50,8\left[\mathrm{~mJ} / \mathrm{m}^{2}\right]$, składowa dyspersyjna wynosi $\gamma_{w D}=48,5\left[\mathrm{~mJ} / \mathrm{m}^{2}\right]$, składowa polarna wynosi $\gamma_{\mathrm{wP}}=2,3\left[\mathrm{~mJ} / \mathrm{m}^{2}\right]$;

- glikolu etylowego, dla którego: swobodna energia powierzchniowa wynosi $\gamma_{w}=48,0\left[\mathrm{~mJ} / \mathrm{m}^{2}\right]$, składowa dyspersyjna wynosi $\gamma_{w D}=29,0\left[\mathrm{~mJ} / \mathrm{m}^{2}\right]$, składowa polarna wynosi $\gamma_{\mathrm{wP}}=19,0\left[\mathrm{~mJ} / \mathrm{m}^{2}\right]$;

- formamidu, dla którego: swobodna energia powierzchniowa wynosi $\gamma_{w}=56,90\left[\mathrm{~mJ} / \mathrm{m}^{2}\right]$, składowa dyspersyjna wynosi $\gamma_{w D}=23,50\left[\mathrm{~mJ} / \mathrm{m}^{2}\right]$, składowa polarna wynosi $\gamma_{w P}=33,40\left[\mathrm{~mJ} / \mathrm{m}^{2}\right][15]$.
Do wytworzenia jednozakładkowych połączeń użyto blachy ze stopu aluminium 7075, dla których przewidziano 2 warianty przygotowania powierzchni. Jeden wariant przewidywał przygotowanie próbek tylko przez ich odtłuszczenie, drugi natomiast przewidywał przygotowanie powierzchni przez aktywację plazmą niskotemperaturową. Modyfikacja przy zastosowaniu plazmy niskotemperaturowej była prowadzona przy następujących parametrach: moc urządzenia $300 \mathrm{~W}$, napięcie pracy $18 \mathrm{kV}$, przepływ argonu $16 \mathrm{l} / \mathrm{min}$ i stały czas ekspozycji wynoszący $60 \mathrm{~s}$. Zasadę działania urządzenia do wytwarzania plazmy pokazano na rysunku 1.

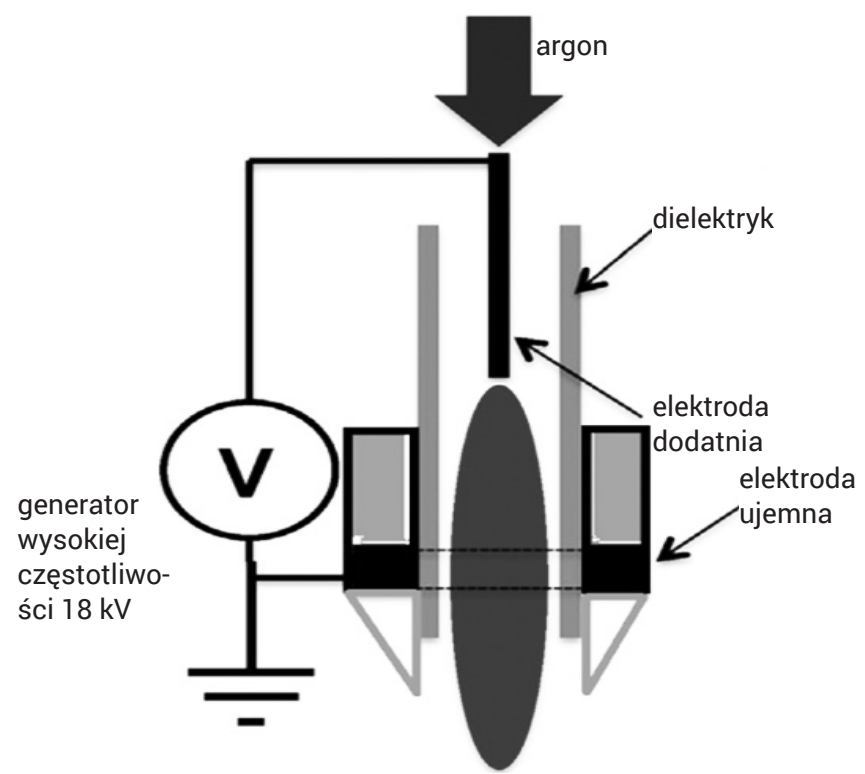

Rys. 1. Schemat urządzenia do wytwarzania plazmy niskotemperaturowej

Fig. 1. Schematic of a device for producing low temperature plasma

Wymiary wytworzonego połączenia jednozakładkowego zostały przedstawione na rysunku 2. Grubość warstwy kleju była stała i wynosiła 0,18 mm. Stała grubość warstwy została uzyskana przez zastosowanie drucików miedzianych o grubości 0,18 mm jako elementów dystansowych. W badaniach zastosowano klej przemysłowy na bazie żywicy metakrylowej - Agomet F330 oraz dwie kompozycje klejowe na bazie żywicy epoksydowej Epidian 57+60\% wag. utwardzacza PAC oraz Epidian $5+70 \%$ wag. utwardzacza PAC. Klej Agomet F330 jest klejem dwuskładnikowym, żywica+utwardzacz w postaci proszku, utwardzacza dodano w ilości 3\% wag., a klej charakteryzuje się dobrymi własnościami wytrzymałościowymi (wg danych producenta wytrzymałość na ścinanie to $33 \mathrm{MPa}$ dla stopów aluminium) [14]. Połączenia klejowe z wykorzystaniem kleju Agomet F330 były badane po upływie 24 h od momentu klejenia.

Tablica I. Skład chemiczny stopu aluminium 7075

Table I. Aluminum alloy 7075 chemical composition

\begin{tabular}{|c|c|c|c|c|c|c|c|c|}
\hline \multicolumn{10}{|c|}{ Aluminium 7075} \\
\hline Pierwiastek & $\mathrm{Si}$ & $\mathrm{Fe}$ & $\mathrm{Cu}$ & $\mathrm{Mn}$ & $\mathrm{Mg}$ & $\mathrm{Cr}$ & $\mathrm{Zn}$ & $\mathrm{Ti}$ \\
\hline Wartość zakres lub max, \% & 0,40 & 0,50 & $1,20 \div 2,00$ & 0,30 & $2,10 \div 2,90$ & $0,18 \div 0,28$ & $5,10 \div 6,10$ & 0,20 \\
\hline
\end{tabular}

Tablica II. Wybrane własności mechaniczne stopu aluminium 7075

Table II. Aluminum alloy 7075 selected mechanical properties

\begin{tabular}{|c|c|c|c|}
\hline \multicolumn{4}{|c|}{ Aluminium 7075} \\
\hline Wytrzymałość na rozciąganie $\mathbf{R}_{\mathrm{m}}, \mathbf{M P a}$ & Umowna granica plastyczności $\mathbf{R}_{\mathrm{p} 0,2}, \mathbf{M P a}$ & Twardość $\mathrm{HB}$ & Wydłużenie $\mathbf{A}_{5}, \%$ \\
\hline $480 \div 540$ & $390 \div 470$ & $104 \div 157$ & $6 \div 8$ \\
\hline
\end{tabular}


Próbki, dla których do połączenia wykorzystano kompozycje klejowe na bazie żywic epoksydowych sieciowano dwuetapowo. Wstępnie $\mathrm{w}$ temp. $35^{\circ} \mathrm{C}$ przez czas $1,5 \mathrm{~h}$ i następnie kolejne $1,5 \mathrm{~h}$ w temperaturze $100{ }^{\circ} \mathrm{C}$. Połączenia klejowe były badane na maszynie wytrzymałościowej po upływie kolejnych $24 \mathrm{~h}$. Badania wytrzymałościowe wytworzonych połączeń zakładkowych były prowadzone na uniwersalnej maszynie wytrzymałościowej Tinius Olsen H25KT. Prędkość przesuwu trawersy podczas prób wynosiła $2 \mathrm{~mm} / \mathrm{min}$.
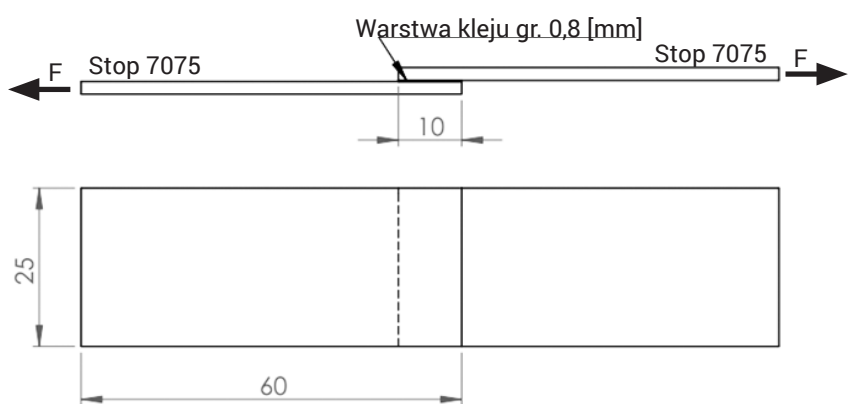

Rys. 2. Schemat próbki do badań - połączenie jednozakładkowe Fig. 2. Diagram of the test sample - one-way connection

\section{Wyniki badań}

W tabeli 3 przedstawiono uśrednione wartości energii powierzchniowej uzyskane w wyniku pomiarów kąta zwilżania wymienionymi wyżej cieczami pomiarowymi powierzchni próbek ze stopu 7075. Wartości swobodnej energii powierzchniowej zostały wyliczone metodą Owens-Wendt-Rabel-Kaelble'a (OWRK) przy zastosowaniu 4 cieczy pomiarowych [2].

Na rysunku 3 przedstawiono przekładowe zdjęcia zwilżania przez kroplę wody powierzchni stopu 7075 dla 2 wariantów przygotowania powierzchni. Na rysunku 3a przedstawiono kroplę wody zwilżającą powierzchnię nie modyfikowaną, odtłuszczoną alkoholem etylowym. Kąt zwilżania wodą dla takich warunków wyniósł $79,3^{\circ}$.

a) $\mathrm{CA}$ 니 79.3 CA [P] 79.3

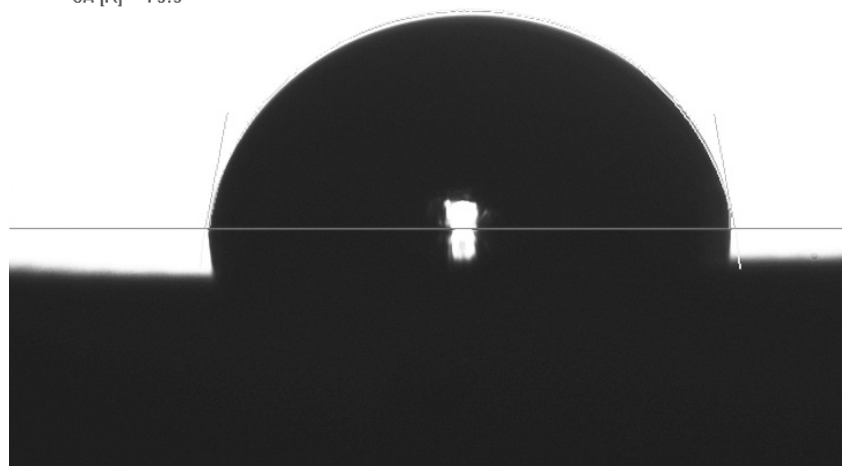

$\mathrm{Na}$ rysunku 3b przedstawiono natomiast kroplę wody zwilżającą powierzchnię odtłuszczoną alkoholem etylowym oraz dodatkowo aktywowaną działaniem plazmy niskotemperaturowej. Kąt zwilżania wodą dla takich warunków wyniósł $42,7^{\circ}$.

W wyniku działania strumieniem plazmy niskotemperaturowej zaobserwowano wzrost SEP o ok. 43\%, w tym składowej dyspersyjnej o ok. 13\% i składowej polarnej o 316\%. Znaczący wzrost SEP wskazuje, iż zaproponowana modyfikacja powierzchni działa i wpływa znacząco na zwiększenie polarności powierzchni. Należy oczekiwać, iż połączenie klejowe $z$ w ten sposób modyfikowaną powierzchnią powinny cechować się większą wytrzymałością.

$\mathrm{Na}$ podstawie przeprowadzonych badań wytrzymałościowych wytworzonych połączeń zakładkowych z zastosowaniem 2 metod przygotowania powierzchni oraz kleju Agomet F330, oraz kompozycji klejowych na bazie żywic Epidian 5, Epidian 57 oraz utwardzacza PAC otrzymano wyniki, które zestawiono na rysunku 4.

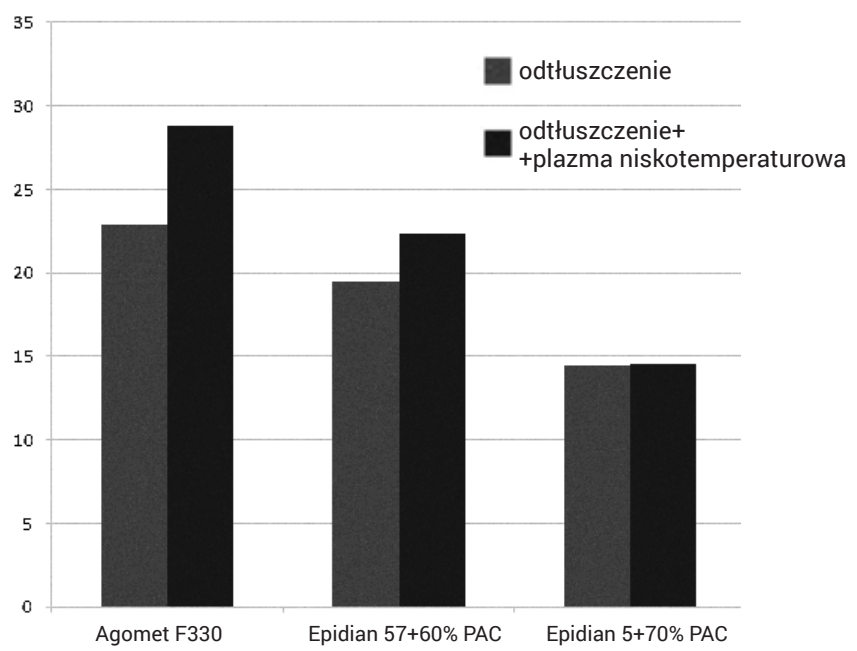

Rys. 4. Naprężenia niszczące $w$ połączeniach klejowych pracujących na ścinanie

Fig. 4. Failure stresses in shear working glued joints
CA [R] 42.7

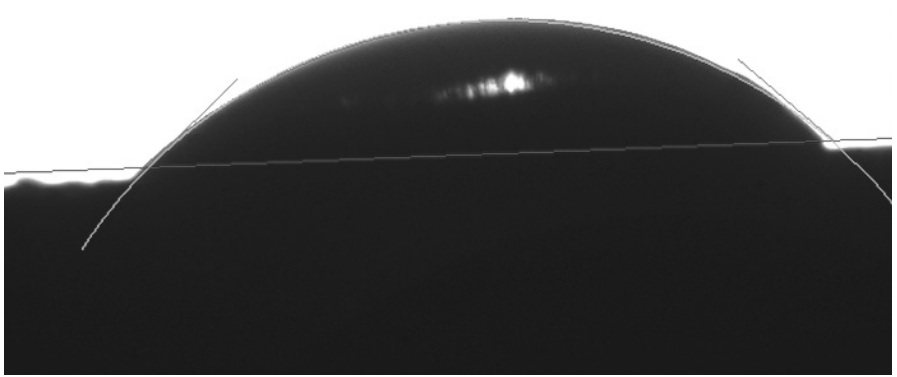

Rys. 3. Zdjęcia kropli wody zwilżającej powierzchnię stopu 7075; a) powierzchnia po odtłuszczeniu, b) powierzchnia dodatkowo aktywowana plazmą niskotemperaturową

Fig. 3. Photos of water drop dampening surface of alloy 7075 ; a) surface after degreasing, b) surface additionally activated by low temperature plasma

Tablica III. Swobodna energia powierzchniowa (SEP) i jej składowe dla stopu aluminium 7075 Table III. Free surface energy (FSE) and its components for aluminum alloy 7075

\begin{tabular}{|c|c|c|c|c|c|c|}
\hline & \multicolumn{3}{|c|}{ Aluminium 7075 po odtłuszczaniu } & \multicolumn{3}{|c|}{$\begin{array}{l}\text { Aluminium } 7075 \text { po odttuszczaniu } \\
\text { i obróbce plazmą niskotemperaturową }\end{array}$} \\
\hline & $\mathrm{SEP}\left[\mathrm{mJ} / \mathrm{m}^{2}\right]$ & $\begin{array}{c}\text { Składowa dys- } \\
\text { persyjna }\left[\mathrm{mJ} / \mathrm{m}^{2}\right]\end{array}$ & $\begin{array}{l}\text { Składowa polar- } \\
\text { na }\left[\mathrm{mJ} / \mathrm{m}^{2}\right]\end{array}$ & $\mathrm{SEP}\left[\mathrm{mJ} / \mathrm{m}^{2}\right]$ & $\begin{array}{c}\text { Składowa dys- } \\
\text { persyjna }\left[\mathrm{mJ} / \mathrm{m}^{2}\right]\end{array}$ & $\begin{array}{l}\text { Składowa polar- } \\
\text { na }\left[\mathrm{mJ} / \mathrm{m}^{2}\right]\end{array}$ \\
\hline Wartość średnia & 37,1 & 31,6 & 5,4 & 53,2 & 36,0 & 17,1 \\
\hline
\end{tabular}




\section{Wnioski}

Na podstawie przeprowadzonych badań można sformułować następujące wnioski:

1. Stwierdzono wzrost swobodnej energii powierzchniowej dla blach stopu aluminium 7075 modyfikowanych plazmą niskotemperaturową i w stosunku do blach niemodyfikowanych wzrost ten wynosił ok. 43\%, co ważniejsze wzrost składowej polarnej wynosił $316 \%$.

2. Dla kleju Agomet oraz dla kompozycji Epidian 57+PAC zanotowano wzrost wytrzymałości połączenia. Wzrost ten wynosi ok. 25\% dla kleju Agomet F330 i ok. 15\% dla kompozycji Epidianu 57+PAC. Dla kompozycji Epidian 5+PAC nie odnotowano wzrostu wytrzymałość po zastosowaniu aktywacji powierzchni plazmą niskotemperaturową.

3. Z przeprowadzonych badań można wywnioskować, iż aktywacja powierzchni i tym samym wzrost energii powierzchniowej przekłada się na wzrost wytrzymałości połączenia klejowego, jednak w omawianym przypadku miało to odzwierciedlenie dla 2 z 3 przebadanych klejów. Zatem przed zastosowaniem aktywacji przy pomocy plazmy niskotemperaturowej w odniesieniu do konkretnego materiału i kleju należy przeprowadzić badania wstępne, aby potwierdzić celowość stosowania tej metody aktywacji.

\section{Literatura}

[1] Anagreha N., Dorn L.: Influence of low-pressure plasma treatment on adhesive bonding between polybutylene terephthalat (PBT) and aluminum, International Journal of Adhesion \& Adhesives, 25, 2005, pp. 165-172.

[2] Baldan A.: Adhesion phenomena in bonded joints, Intern. Journal of Adhesion \& Adhesives, 38, 2012.

[3] Bárdos L., Baránková H.: Cold atmospheric plasma: sources, processes, and applications, Thin Solid Films, 2010, 518, pp. 6705-6713.

[4] Gao Z., Sun J., Peng S., Yao L., Qiu Y.: Surface modification of a polyamide 6 film by He/CF4 plasma using atmospheric pressure plasma jet, Appl. Surf. Sci., 256, 2009, pp. 1496-1501.

[5] Godzimirski J.: Wytrzymałość doraźna konstrukcyjnych połączeń klejowych, WNT, Warszawa, 2002.

[6] Kłonica M., Kuczmaszewski J.: Badania porównawcze wytrzymałości na ścinanie klejowych połączeń zakładkowych stali $316 \mathrm{~L}$ po „szokach termicznych", Przetwórstwo Tworzyw Sztucznych, 2 (164) 2015, s. 125-130.

[7] Mandolfino C., Lertora E., Gambaro C.: Influence of cold plasma treatment parameters on the mechanical properties of polyamide homogeneous bonded joints, Surface \& Coatings Technology, 313, 2017, pp. 222-229.
[8] Mirski Z., Wróblewski R., Gołembiewski A.: Odporność połączeń klejowych na oddziaływanie wysokiej temperatury, Przegląd Spawalnictwa, nr $10 / 87,2015$, s. 108-114.

[9] Rudawska A., Danczak I., Müller M., Valasek P.: The effect of sandblasting on Surface properties for adhesion, Intern. Journal of Adhesion \& Adhesives, 70, 2016, pp. 176-190.

[10] Stryczewska H.D.: Technologie zimnej plazmy. Wytwarzanie, modelowanie, zastosowania, Elektryka, Zeszyt 1, 2011, s. 41-61.

[11] Vendemiatti C., Hosokawa R.S., Rangel R.C.C., Bortoleto J.R.R., Cruz N.C., Rangel E.C.: Wettability and surface microstructure of polyamide 6 coated with SiOXCYHZ films, Surf. Coat. Technol., 275, 2015, pp. 32-40.

[12] Zhu L., Teng W., Xu H., Liu Y., Jiang Q., Wang C., Qiu Y.: Effect of absorbedmoisture on the atmospheric plasma etching of polyamide fibers, Surf. Coat. Technol., 202, 2008, pp.1966-1974.

[13] Żenkiewicz M.: Adhezja i modyfikowanie warstwy wierzchniej tworzyw wielkocząsteczkowych, WNT, Warszawa 2000

[14] Karta technologiczna produktu Agomet F330.

[15] Dokumentacja goniometru firmy Krüss, Hamburg, 2009. 